\title{
Proposed Maturity Model for Industry-Academia Collaboration
}

\author{
Vedavyas M G \\ Faculty of Management \\ PES University 100 Feet Ring Road, Banashankari 3rd Stage \\ Bangalore, 560070 \\ vedavyas@pes.edu
}

\begin{abstract}
While the Industry and Academia work very closely in western countries, it is at its infancy in terms of the output, in the Indian context. If the national mission for Digital India and Innovation is to be achieved, the Industry -Academic collaborations needs to be strengthened as well as scaled in a major way. The author has spent nearly three decades in both industry and academics. This paper proposes a fivestage Collaboration Maturity Model for any academic institute to follow in order to extract value from the collaboration. The model is a very practical implementable model that guides the growth of the collaboration from initial engagement to close-knit partnership.
\end{abstract}

Keywords: Collaboration, Maturity, Model, Innovation, Industry, Academic

\author{
Vedavyas M G \\ Faculty of Management \\ PES University 100 Feet Ring Road, Banashankari 3rd Stage \\ Bangalore, 560070 \\ vedavyas@pes.edu
}

\section{Introduction}

The economic progress of any nation can be traced to a combination of its natural resources, intellectual resources and financial capital. The quality of a country's resources can improve only with literacy, education and innovation in producing new or better products and services for the global market. Research and Innovation coming out of industry-academic collaboration goes a long way in creating national competency. There is an urgent need in India for the industry and academia to come together to produce innovation and entrepreneurship that can leverage the rich talent available for economic prosperity.

\section{Economic context for collaboration}

India will have 400 Million youth in the 25 to 35 years age group in the next few years. Inability to keep them productively occupied can spell disaster for the nation. Innovation is the key to peace and prosperity through entrepreneurship. This needs knowledge creation and capital investment. The first can come from the academia and the second from industry. Applying knowledge to solve industry problems creates opportunities for growth. Hence, the need for collaboration is paramount.

\section{Why should industry and academia collaborate?}

Apart from the national level economic reasons noted earlier, there are industry level reasons why the 
industry and academia should collaborate. They are briefly mentioned below.

प It helps reduce the skill gap between what the industry needs (skill consumers) and what the academia produces (skill producers)

口 By working closely with industry, students and faculty accelerate their learning and understand problems first-hand

( Given the squeeze on capital for industry, academia can act as low-cost extensions of their own research labs

口 Any new invention by academia cannot be scaled to production unless the knowledge is transferred to industry through collaboration

\section{What are the challenges of collaboration?}

All the industry people and the academicians agree that there should be collaboration. If so, why is the collaboration in India at such a low level of engagement? The answers are not difficult to find.

The industry feels

口 Academicians are theorists - not rooted in practicality of industry

口 Research happening in academia are mostly irrelevant to industry

口 Academicians are interested in research only to the extent of publishing papers and not extending it to solve real-life problems

u The pace and methods of working of the academia and industry do not match

․ The academia feels

口 Industry has no genuine interest in working with the academia

口 Industry does not understand academic rigor in research and look for quick solutions

口 Industry considers money spent on academia as expense and not investment

口 Industry has no patience

While we may agree or disagree on the validity of each of these points, it is beyond the scope of this present paper. This paper focuses on how to collaborate rather than on why not to collaborate.

\section{Need for a Maturity Model}

India has more than 700 universities and more than
31,000 colleges. But the industry-academic collaboration is limited to a few universities like the IITs, IISc, NIT and a few other large institutes. Compared to any advanced economy, this is a miniscule figure. Given the global context today, it is imperative that the industry and academia collaboration needs to be strengthened and speeded up. It takes many years before the collaboration can yield measurable results. Institutes and industry alike, that are looking to collaborate need a collaboration model that they can follow to ensure achievement of desired results. Currently, many institutes are groping in the dark about how to go about such collaboration.

This paper introduces a Collaboration model that industry and academia can follow.

\section{The Collaboration Maturity Model characteristics}

The collaboration model proposed here has the following characteristics

1) It surmises that most collaborations go through life-cycle phases from initial engagement to trusted partnerships

2) It divides the collaboration life-cycle into five levels

3) Each maturity level is progressive

4) Different collaborations may mature in different durations depending upon the quality of governance and the top management commitment and support

5) Though rare, it is possible for collaborations to skip some lower levels of the maturity model

6) The intention of suggesting this model is that it should act as a guide for institutes who are unable to start collaborations are having started, do not know how to progress

\section{Collaboration Level 1 - Testing the Waters}

This is the entry level. At this level, neither the industry nor the institute are familiar with each other. At this level, most of the interaction is transaction based and 'hands-off'.

\section{Examples of transactions at this level are}

1) Provide student internships - This is obviously an easy first step that does not involve investment or governance overhead. Easy to give and easy to take.

2) Provide used equipment/kits - Again, this is a one- 
time type of transaction with no continuous engagement.

3) Provide scholarships - The industry can provide a few scholarships that helps build its image at the institute. This is once a year transfer of money, with no responsibility for administering it.

It is easy to see that at Level 1 of collaboration, both parties are testing the waters, with short-term focus. Any collaboration initiative with these characteristics can be considered to be at Level 1 .

\section{Collaboration Level 2 - Engaged Interaction}

This is the second level of the collaboration model. Having gone through the first level, both parties now know how each partner works, what can possibly create value for the other party and so on. Both the parties engage with each other unlike the hands-off approach of Level 1. However, the engagement is infrequent, on-off type.

\section{Examples of engagement at this level are}

1) Advisory Board participation by industry - This could be for curriculum or at Institution level

2) Periodic Guest lectures

3) Periodic industry visits by students/faculty

4) Industry sabbatical at institute

5) Sponsoring and participating in industry relevant seminars

It is easy to see that the engagement at this level is deeper than at Level 1 and has medium term focus, but still falls short of real collaboration.

\section{Collaboration Level 3 - Continuous Interaction}

This is the third level of the collaboration model. Having gone through the first two levels, both parties now know the strengths and how to leverage them. At this level, they start engaging in activities that needs continuous senior level governance, contracts, processes etc. The collaboration starts getting discussed at different layers of the organizations.

Examples of engagement at this level are

1) Consulting assignments for the institute faculty in the industry

2) Establishment of Chairs and Labs at the institute by the industry
3) Joint certification courses with the industry for students and industry employees

4) Joint publication of books, case studies, papers etc.

At this level of engagement, it is obvious that the partners have started leveraging the partnership for mutual benefit. Initiatives require both parties to work closely in teams.

\section{Collaboration Level 4 - Integration of intellectual capital}

This is the fourth level of the collaboration model. Having gone through the first three levels, both parties now trust each other and are keen to contribute in the success of the other party. They want to make a difference to the other party to the extent that the other party gets a competitive advantage in the industry. There is mutual learning, integration of intellectual capital and joint commercial orientation.

Examples of engagement at this level are

1) Establishment of Centres of Excellence - These are joint research facilities in a chosen domain area where researchers from both teams work together to produce intellectual capital that can hopefully be commercialised

2) Continuing education for industry employees where the institute establishes exclusive learning facilities backed by latest academic knowledge

\section{3) Contract Research}

At this level of engagement, it is obvious that the partners trust and understand each other enough to develop IPR.

\section{Collaboration Level 5 - Creating engines of the economy}

This is the fifth and final level of the collaboration model. At this level, the partners jointly address the social issues of job creation by collaborating to commercialize their joint IPR. They start making a difference jointly to the society around them. This is the level that is innovation-led and job-creating.

Examples of engagement at this level are

1) Joint venture entities creating social prosperity 
2) Jointly adopting smaller struggling industries around to enhance their level of competency

3) Collaboration initiatives becoming strategic for the success of both the parties

4) Having a say in the growth direction of the partner

5) Establishing a shared community of innovation

At this level of engagement, the partners are tightly coupled with each other. Each considers the other an essential element of its own success. Both are engaged jointly in developing the society around them. This then, is the true goal of collaboration.

\section{Conclusions}

From the foregoing discussion of the author suggested conceptual model of industry academia collaboration, it is obvious that it will generally take a few years for any collaboration to achieve its true goals. We should not ignore the importance of top level commitment and support as well as the mechanism for governance of the collaboration. Further study and work are required in the areas of
(a) Governance,
(b) Assessment methodology for determining level of the maturity
(c) Tools and templates to help acceleration of the collaboration process

(d) Sharing of best practices in the area of collaboration.

\section{References}

This is an original article by the author and there are no references.

\section{Acknowledgement}

The author wishes to thank Dr. K N B Murthy, Vice-Chancellor of PES University for reviewing the ideas and concepts used in this paper. 